\title{
Correction to: DNA methylation-based reclassification of olfactory neuroblastoma
}

David Capper · Nils W. Engel · Damian Stichel · Matt Lechner · Stefanie Glöss · Simone Schmid ·

Christian Kölsche · Daniel Schrimpf · Judith Niesen · Annika K. Wefers · David T. W. Jones · Martin Sill •

Oliver Weigert · Keith L. Ligon · Adriana Olar · Arend Koch · Martin Forster · Sebastian Moran · Oscar M. Tirado ·

Miguel Sáinz-Jaspeado - Jaume Mora - Manel Esteller - Javier Alonso - Xavier Garcia del Muro · Werner Paulus .

Jörg Felsberg · Guido Reifenberger · Markus Glatzel · Stephan Frank · Camelia M. Monoranu • Valerie J. Lund ·

Andreas von Deimling · Stefan Pfister · Rolf Buslei · Julika Ribbat-Idel · Sven Perner · Volker Gudziol ·

Matthias Meinhardt · Ulrich Schüller ${ }^{1,2,3,4}$ (])

Published online: 9 August 2018

(c) Springer-Verlag GmbH Germany, part of Springer Nature 2018

\section{Correction to: Acta Neuropathologica}

https://doi.org/10.1007/s00401-018-1854-7

In the original publication, the second name of the twentieth author was incorrect. It should read as 'Miguel
Sáinz-Jaspeado'. The original publication of the article has been updated to reflect the change. This correction was authored by Ulrich Schüller on behalf of all authors of the original publication.

The original article can be found online at https://doi.org/10.1007/ s00401-018-1854-7.

Ulrich Schüller

u.schueller@uke.de

1 Center for Neuropathology, Ludwig-Maximilians-University, Munich, Germany

2 Institute of Neuropathology, University Medical Center Hamburg, Hamburg, Germany

3 Department of Pediatric Hematology and Oncology, University Medical Center, Hamburg-Eppendorf, Germany

4 Research Institute Children's Cancer Center Hamburg, Hamburg, Germany 